\title{
Revisiting Living in Limbo to Illustrate a Pastoral Psychological Understanding of Transition from Military to Civilian Life
}

\author{
Jan Grimell ${ }^{1}$ (1D \\ Published online: 25 May 2019 \\ (C) The Author(s) 2019
}

\begin{abstract}
The transition from military to civilian life includes a multitude of challenges for service members and their significant others. This transfer from one context to another can include, but is not limited to, a need for an identity shift, cultivation of an alternate mind-set, social reorientation, a search for employment, grief and sadness due to the loss of camaraderie, and/or experiences of alienation and estrangement from civilian society. Although the social sciences dominate this research field and dub it 'transition,' the ambiguity of the process can be further advanced through pastoral psychology. This article rethinks and reinterprets qualitative data to develop a pastoral psychological understanding of veterans through Capps and Carlin's lens of living in limbo. This pastoral psychological construct embraces the ambiguity of the transition to civilian life and addresses it as a potentially complex and acute limbo situation. This construct can resonate with both veterans and significant others while also assisting pastors in providing care and counseling.
\end{abstract}

Keywords Military · Veteran · Transition · Living in limbo · Pastoral psychology

Entry into military service often implicates a dramatic culture and identity shift as individuals leave civilian society behind to dedicate their lives to service, including deployments to war zones (Beder 2012; Devries et al. 2012; Hall 2012a, b; Strachan 2006; Verrips 2006; Wilson 2008). Military cultures shape robust military identities that enable personnel to perform extremely taxing actions in high-stakes deployment situations (Ben-Ari 1998; Bryan and Morrow 2011). However, war zone stresses and acts can violate one's moral code. Participation in war zone activities, or even merely bearing witness to transgression and violence, may mark the human psyche in several ways. Posttraumatic stress disorder (PTSD), as described by The Diagnostic and Statistical Manual of Mental Disorders 5 (American Psychiatric

Jan Grimell

j.m.grimell@vu.nl

1 Vrije Universiteit Amsterdam (Amsterdam Centre for the Study of Lived Religion), De Boelelaan 1105, 1081 HV Amsterdam, The Netherlands 
Association 2013), may be the best known and most recognized psychiatric trauma that can result from war zone deployments. Moral injury, on the other hand, is a relatively recent construct, yet it has drawn growing interest because it involves perceived internal conflicts and potential injuries during and/or after military service that may burden veterans morally and emotionally (Drescher et al. 2011; Litz et al. 2009).

Until recently, the construct of moral injury has been primarily elaborated within the field of psychology. However, the understanding of such moral issues may also be advanced through religious/spiritual lenses and served by religious/spiritual caregivers, sometimes in collaboration with clinicians (Bobrow et al. 2013; Koenig et al. 2017; Wortmann et al. 2017). Researchers even suggest that this concept may be a new name for something that has been addressed by caregivers within wisdom traditions throughout history (Lindsay et al. 2016). In addition to the psychiatric construct of PTSD and the psychological construct of moral injury, there is also the fact that military communal life is very different from life as a civilian. This suggests that the transition from military to civilian life, and the reintegration into civilian society, may include other types of challenges for military personnel, such as the need for an identity shift and construction of a new cultural mind-set, fuller reorientation toward family and civilian peers, the need for new employment, and grief and sadness due to the perceived loss of camaraderie, rank, and prestige coupled with experiences of alienation and estrangement from civilian society, to name just a few (Adler et al. 2011a, b; Blackburn 2017; Bragin 2010; Coll et al. 2012; Moore 2012; Verey and Smith 2012; Woodward 2008). In other words, the transition from military to civilian life may be understood as a movement from one cultural identity to another cultural identity.

Whereas psychiatric (i.e., PTSD) and psychological (i.e., moral injury) constructs illustrate a clinical understanding of and approach to some of the issues veterans have to live with in the aftermath of military service, radically fewer theological and pastoral psychological constructs have been proposed in relation to these constructs (for example, see Doehring and Ramsay 2019; Graham 2017; Moon 2019; Rambo 2010). Yet, it is a crucial pastoral psychological quest to advance the understanding of the issues and burdens that result from military service as individuals build new lives as civilians (Grimell 2019; Liebert 2019; Moon 2015; Sippola et al. 2009; Stallinga 2013).

Donald Capps and Nathan Carlin's (2010) Living in Limbo: Life in the Midst of Uncertainty offers an interesting and promising way to approach and present a pastoral psychological understanding of veterans, and their work deserves more attention. The purpose of this article is therefore to revisit and apply Living in Limbo to qualitative research so as to enrich the pastoral psychological perspective that can be utilized to understand veterans and their families. This limbo lens may also provide for a powerful pastoral conceptualization of current life situations among care seekers that can nurture mutual understandings and hope amid distress, worry, frustration, anger, dread, and despair.

I propose and advocate a broad approach to and for veterans for several reasons. A veteran may approach a pastor prior to a diagnosis, and the pastor may not be particularly familiar with concepts such as PTSD and moral injury; even so, the pastor may be powerfully effective as an agent of hope and/or as a care provider. This limbo lens may serve veterans both with and without PTSD and/or moral injury and may also resonate with family members (who themselves have varying familiarity with such concepts). Furthermore, in the Scandinavian context, PTSD is diagnosed in approximately $5 \%$ of veterans, but many veterans do have some connection to religious communities - if not personally, often via family members - and thus could potentially find a route to a pastor for counseling and care regarding struggles related to 
military service under such a broader approach (Grimell 2018b). Additionally, a broader approach allows for fine-tuning on the theological level to better aid individual care seekers.

This article rethinks and reinterprets qualitative research so as to illustrate a pastoral psychological understanding of veterans through the lens of limbo. The research data are presented both through a review and through a recently completed longitudinal and qualitative research project titled Reconsidering the Uniform (Grimell 2018a). This research project in practical theology was launched in 2013 and followed 19 Swedish service members during their transitions from military to civilian life and, in many cases, their return to part- or fulltime military service. The interview phase included three annual interviews per participant and occurred from 2013 to 2016 . The purpose of the project was to explore and describe existential and/or religious dimensions in identity reconstruction over an extended period of time; this was motivated by the paucity of such longitudinal, empirical, and theological studies. The project will be explained in more detail later.

This article continues with a review of research in American and British contexts on the transition from military to civilian life. It then highlights elements from the Reconsidering the Uniform project and proceeds with a conceptualization of Capps and Carlin's (2010) Living in Limbo, which then leads into the discussion and conclusion.

\section{Review of the qualitative research}

This review includes relevant qualitative research (within the social sciences) on the topic of transition from military to civilian life that is tailored to identity issues (i.e., who I am, where I am going, my place in the world) within North American and British contexts. This is quite a limited field, and the review begins with the oldest contribution and then works its way forward in time.

Drops (1979) conducted a study that addressed changes in self-concept and identity during this transition and compared the data from questionnaires completed by 40 U.S. servicemen with interview data garnered from 10 former servicemen who had left active service between one month and 12 years prior to the interview. Of the 10 who were interviewed, two men had undergone major identity changes, one had changed his self-concept, and the other seven were still in the process of transitioning or had apparently changed very little from a self-identity perspective. Leaving military service tended to be a positive experience, though adjusting to civilian life and obtaining civilian employment were emotional experiences that most men (the U.S. armed forces at the time were not very inclusive of females) found difficult.

Yanos (2004) explored the perceptions of three recently retired U.S. Air Force officers and their wives concerning adjustment to civilian life and their general well-being through in-depth personal interviews. This study suggested that Air Force officers require considerable amounts of time for the transition to retirement. Personal identity is disrupted due to the loss of the career role, and general well-being is negatively affected by the transition to retirement. Military retirees represent a group of individuals whose retirement may begin as early as 42 years of age. Thus, these individuals often transition to a new work setting within a culture that is unfamiliar to them. Yanos's study developed a multidimensional model of adjustment to retirement that considers retirement to be a precipitating event and addresses changes in the domains she delineated of economic impact, social support, identity reconstruction, and physical and mental health. Identity reconstruction and mental health represented the areas of greatest challenge. 
Savion (2009) also conducted a study within an American context wherein she explored the life transitioning experience and the return to civilian society among recently retired military officers. Ten participants who had been living in civilian society for two to five years were purposefully selected. Savion offered the following conclusions:

- Life transitioning experience is expressed in terms of how an individual conceptualizes self in relation to the culture change.

- Adjusting to a different environment is an evolutionary process for individuals exchanging a structured culture for an unstructured culture.

- Navigating the life transition process of letting go of the old situation and starting anew involves a shift in thinking, being, and doing.

- The life transitioning experience unfolds in three stages (i.e. an ending, a neutral zone, and a new beginning) as an individual adjusts to a culture change.

- Identity and attitude evolve as an individual becomes more aware of self, others, and the environment.

- Learning is transformative; through self-reflection and self-discovery, one learns to embrace change, which leads to self-renewal.

- A favorable life transition outcome is dependent upon a self-realizing frame of mind. (p. vii)

Brunger et al. (2013) suggested in their qualitative study on 11 ex-service members who had served in the United Kingdom's armed forces that "the transition from military to civilian life is representative of a shift in identity, whereby ex-service personnel must accept identity loss and the inevitable need for change therein" (Brunger et al. 2013, p. 95). Brunger and her colleagues (Brunger et al. 2013) categorized the experiences among the participants within three broad themes: "characteristics of a military life; loss as experienced upon return to civilian life; and the attempt to bridge the gap between these two lives. Transcending these themes was the notion of identity, illustrating that the transition from military to civilian life can be viewed as a shift in sense of self from soldier to civilian” (p. 86).

Burkhart and Hogan (2015) conducted a study that focused on 20 female service members who had transitioned into civilian life. The study was conducted years after the actual transition had taken place; the female service members had served in the Gulf War and the post-Gulf War era. The qualitative design was built on face-to-face and telephone interviews. The analysis of the interview results showed that several participants claimed to have had experienced identity issues. Burkhart and Hogan suggested that the participants' identities became challenged when they re-entered civilian life and furthermore that

life patterns and values of military and civilian life were different, particularly in relation to camaraderie, rules of behavior, and work ethic. This created confusion that led to living two lives as veteran and civilian. The only way participants could maintain their identity within the civilian sector was to reestablish connections with the military, friends from the military, and veteran groups. (p. 122) 


\section{Returning to the research project: Reconsidering the uniform}

This longitudinal project was designed to follow Swedish service members as early as possible in their transition from military to civilian life. The research purpose of the project was to describe existential and/or religious dimensions over a longer period of time (in contrast to one interview occasion) during the service members' evolving identity reconstruction. The project was designed in this way because of a relative shortage of longitudinal, empirical, and theological studies in the Scandinavian context. When considering the research approach and the design of the project as a whole, no similar studies have been found in this context. In addition to this gap, a large proportion of the preexisting research tends to focus on an American context; this suggests that contextual counterweights could be beneficial and enriching, especially from a contrasting area such as Scandinavia. The condensed description and summarized results presented in this section are derived from the author's doctoral dissertation Reconsidering the Uniform (Grimell 2018a).

\section{Sample and interview design}

The participants joined the study through a snowball sampling method in collaboration with a Swedish military regiment. The participants were informed about the study by a letter of information that presented the background of the project (i.e., the need to gain knowledge about the process of transition among service members) and described the purpose of the project, formalities, the research ethics and anonymity, and the intent to publish the findings. The participants also were asked to sign an informed consent agreement. There was no religious or faith requirement for participation in the study. Thus, a purposeful selection of participants was accumulated totaling 16 males and 3 females $(N=19)$ who varied in terms of age, rank, branches, mission experiences, and total years of service.

All of the participants had voluntarily terminated their employment due to varying combinations of the following factors: disappointment in the employer, stagnation of professional/ personal development, curiosity about exploring new avenues in life, retirement opportunities, or completion of employment contracts. More than half of the sample had been deployed to Afghanistan, Kosovo, and/or Mali, and none of the participants had been diagnosed with PTSD.

Over the course of the study, three annual semi-structured interviews (T1-3) were conducted with each participant between 2013 and 2016. The participants selected the location for each of the interviews, and the same researcher (the author of this article) conducted all of the interviews.

\section{Analysis}

The vast body of interview data (i.e., $67 \mathrm{~h}$ and $30 \mathrm{~min}$ ) was fully transcribed and then analyzed and organized using a qualitative data analysis program called Atlas.ti. Through narrative analysis, five overarching themes related to transition and reintegration into civilian society were sifted out and created in close relationship to the storied experiences of transition among the participants. These five transitional themes 
were also developed in relation to a number of subthemes, and the hermeneutical principle for the development of themes and subthemes was that an overall theme would provide an understanding of a subtheme and vice versa. This suggested a reciprocity between overarching themes and more locally emerging experiences called subthemes. The overall themes made it possible to organize and present transitional experiences in a meaningful way, while the subthemes detailed content and nuances (for details, see Grimell 2018a, chapter 4). The five transitional themes and subthemes are as follows:

Transitional themes

(a) Identity issues

\section{Subthemes}

(a1) Asymmetry between military-veteran identities and new civilian identities, where military-veteran identities maintain a dominant position in the self and where perception is filtered through a military-veteran lens

(a2) A clear sense of a military "me"

(a3) Problems in adjusting to new settings

(a4) A slow process of reconstructing a new, meaningful story of who I am as a civilian

(a5) Difficulties in finding meaning and/or motivation in the new civilian life, implying difficulties of reconstructing the story of who I am in becoming a civilian

(a6) Loss of extraordinary community and camaraderie

(a7) Dichotomy between military and civilian worlds/relationships

(b) A pro-militaristic position in the self

(b1) Pride in having served and positive emotions attached to the service

(b2) Consideration of serving part-time or full-time

(b3) Continuation of part-time service

(c1) Feelings of emptiness

(c2) Feelings of grief (or sadness)

(c3) Feelings of bitterness

(c4) Feelings of confusion and/or frustration

(c5) Feelings of anxiety

(c6) Feelings of depression

(c7) Financial worries

(c8) Feelings related to other issues

(d) Satisfaction

(d1) Embracing preexisting or new ways of life (and identities)

(d2) Feelings of gratefulness or gratitude for personal development, experiences, and camaraderie

(d3) Relief due to being free from duties and obligations related to service

(e) The importance of significant others (e1) Partner

(e2) Family

(e3) Others

The next step in the research analysis was to explore and describe existential dimensions in the process of transition from military to civilian life. The guiding principle and idea for this analysis was based on the claim that existential dimensions within these transitional processes were equivalent to the life issues or life questions that the participants pondered and grappled with and articulated during their transition from military to civilian life. The starting point for the analysis was to sift out such issues in their lives. These types of life questions included six salient storied themes that were found in both the participants' interviews and their existential struggles 
within the processes (for details, see Grimell 2018a, chapter 7). The six existential themes and the content-specific issues are as follows.

Existential themes

(1) Identities

(2) Meaningful employment and/or lifestyles

(3) Significant others

(4) Beliefs and values

(5) Sacrifices imposed upon significant others and/or the self

(6) Temporary departure from society to instead

Enveloping oneself in the natural world
Content-specific issues

included life questions such as who am I, where am I going, where is my place in the world

supported the process of transition

assisted or promoted the process of transition

influenced the participants in the process of transition

included life-questions centering

upon the costs of military service in past, present, and future

served as a significant source of

power in the process of transition and in the lives of many participants as they articulated the need to leave society behind for outdoor activities that invoked feelings of peace, serenity, energy, and reflection

The participants' responses suggest that the military stories about who one is (i.e., military identity), or at least who one was, were intertwined with profound experiences of meaning, purpose, camaraderie, community, belonging, and sacrifice that were not easily left behind. By the time of the third interview, rumination over existential questions had led a majority of the participants to return to different forms of military service. Of the 19 participants, nine concluded the study with a hybrid civilian/military lifestyle that included part-time military employment, while another four completely aborted the transition to a civilian life to return to full-time military service. This, however, did not imply that tension and friction between military and civilian issues among the participants was internally resolved and dissolved. Going back to some type of military service was, rather, a self-chosen solution to existential questions that had not found fulfilling answers within the civilian context. Only six participants had completed a full transitional process to civilian life by the study's conclusion via reintegration into civilian society and the construction of meaningful stories and narrative characters within their new lives. Even so, among these participants a pro-militaristic position persisted alongside feelings of peace within themselves within a civilian context.

\section{Living in limbo}

The idea of limbo has traditionally been perceived as a place between heaven and hell, a place set aside for righteous souls who predated Christ and infants who died before they had a chance to be baptized. This idea was shaped in the Middle Ages around the same time as the concept of purgatory. Over the centuries, theologians and church officials debated the distinction between purgatory and limbo; both were commonly considered relatively dark places, but purgatory was often seen as a place of affliction whereas limbo was not. The darkness in limbo was not absolute, nor was it really the deprivation of grace; it simply was not heaven. However, roughly a decade ago a document titled The Hope of Salvation for Infants Who Die without Being Baptized (2007) by the International Theological Commission of the Roman Catholic Church asserted that the concept of limbo had never been officially adopted by the Church and should be viewed as inconsistent with church teachings. This document was 
intended to reassure distressed parents - who thought that their infants who died before they could be baptized would go to limbo - that they instead would see their babies in heaven. The grounds for the commission's assertion were mainly theological, but psychological evidence was also invoked.

Although limbo has been officially rejected by the Roman Catholic Church as an outmoded theological idea, Capps and Carlin (2010) argue that we should not simply leave the idea behind. They recommend instead salvaging the idea in the interest of better understanding the lives of the living. The concept of limbo may be employed in the service of both pastoral care and pastoral psychology. Applying anew the focus to the lives of the living, they suggest that limbo can be any intermediate and/or indeterminate state and/or a place or condition of confinement, neglect, or oblivion. In a sense, limbo is a sort of chronic condition from which humans are never entirely free. But of special interest are the so-called acute limbo situations. Capps and Carlin (2010) list five domains of acute limbo situations, four of which are of specific interest in this article's pastoral psychological attempt to better understand and provide care for veterans and their families.

- Acute limbo situations related to dating, marriage, and committed relationships, e.g., dealing with extended absences of one's partner or spouse due to occupational obligations or educational engagements, the process of terminating a relationship, conflicts of loyalty.

- Acute limbo situations related to occupation, profession, and vocation, e.g., the quandary about which occupation to pursue, professional stress and burdens due to one's obligations and assignments, professional burnout, crossroads in life where one is seriously considering a radical occupational change, transfer from one employment to another.

- Acute limbo situations that include physical and emotional illness, e.g., being injured, being involved in an accident, being depressed, experiencing anxiety, or developing psychosomatic issues.

- Acute limbo situations that involve experiences of dislocation (creating feelings of disorientation), e.g., leaving home to go to college, being placed voluntarily or involuntarily in an institution, being sent to war, being transferred to a new location by one's employer. (pp. 3-5)

Acute limbo situations include different forms of doubt, as when grappling with meaning and purpose of life, when that which seemed self-evident becomes challenged or is doubted or when the discovery of clarity remains elusive. For some persons, a transfer from one familiar occupational setting to another may be experienced as entering a place or condition of confinement, neglect, or oblivion. Another may experience it differently. The degrees of darkness in such a limbo differ. Some situations are experienced as being more distressful than others, but the common types of distress include "anxiety, worry, impatience, frustration, anger, dread, and despair" (Capps and Carlin 2010, p. 6). The duration of acute limbo situations can vary from months to years.

Capps and Carlin (2010) further argue for the importance of delineating a distinction between acute limbo situations and transitions, which they refer to as a concept employed by psychologists to discuss a move from one stage to another (p. 8). They suggest that the word 'limbo' does a better job of conveying the ambiguities because limbo comprises a host of benefits (of not being committed) as well as liabilities (of being disoriented, confused, adrift, useless, without purpose and/or unable to make decisions or achieve desired goals). In addition, limbo can also imply that a person is in a state of confinement or even neglect, 
possibly even in a state of oblivion. In any case, limbo tends to focus on the experience of being in between whereas transition focuses on the passage from one condition to another. Limbo is not heaven, but neither is it hell.

As seen through Capps and Carlin's approach, this pastoral psychological construct of limbo has the potential to ameliorate acute situations because this is not a condition devoid of grace. Even if it feels distant, grace is not absent. The very idea that Christ descends into our daily lives, even when life is lived in limbo, is itself grounds for hope. This hope can help mitigate distress; hope can play a significant role in guiding and sustaining persons in acute limbo situations. To cultivate a spirit of hopefulness is therefore of critical importance during acute limbo situations. An awareness of what hope is, what experiences of hope may involve, what may threaten it, and conversely what may sustain it, is important to foster. This awareness can play a vital role in a person's ability to respond to the love of God when he or she is in a perceived dark place.

When applying this idea of limbo to veterans (and their significant others), it may initially seem as though the word 'hope' would be more appropriately used for a transition with a specific end. The initial phase of transitioning into civilian life may not be fully understood as limbo but rather more as a liminal process of grieving. Even so, after an extended struggle to fully reintegrate into civilian life, the limbo understanding may better resonate with subjective experiences and the specific need for hope. Meanwhile, a diversity of personalized definitions of hope may develop among individual care seekers during this process. Veterans with PTSD and/or moral injury, who live the remainder of their lives with the horrors and terrors of war, likely deal with hope in decidedly different ways than veterans struggling with existential issues of being in between. And just as hope in limbo may mean different things to different veterans, it may also hold varying meanings for significant others. To some veterans, hope may resonate with the experience of belonging to a community that is marginalized, and thus even when these veterans embrace hopelessness they may not necessarily be despairing as they are not alone in that hopelessness (De La Torre 2017). Others may cultivate hope by seeking forgiveness and reconciliation, which can ameliorate and potentially heal a moral injury or suffering relationship with significant others. The pastor should serve as an agent of hope during this process; the pastor's mission is to explore what hope means to the specific care seeker (Capps 1995).

\section{Discussion}

In line with Capps and Carlin (2010), the psychological concept of transition equates a transfer or move from one condition or stage to another, and this view has had a strong effect on the research involving service members and veterans. Generally speaking, research on the transition from military to civilian life is so profoundly influenced by psychology that the word 'transition' seems to be both a standard expression and a concept automatically employed when discussing the topic of transitioning from military to civilian life. Yet this transfer may include both explicit challenges (e.g., financial concerns, employment seeking, moving to a new area, losing a social network) as well as implicit issues (e.g., biological, social, psychological, religious/spiritual) that service members confront during their movement from a military context to a civilian one (Adler et al. 2011a, b; Blackburn 2017; Bragin 2010; Beder 2012; Lifton 1992; Moore 2012; Tick 2005; Verey and Smith 2012). Research on military-to-civilian-life helps to unveil the complexity of such processes and suggests that the 
word 'transition' may not fully cover the ambiguity of leaving military service and the military community to reintegrate into civilian society and life. Researchers within the field presumably have knowledge and awareness of the many layers of this process, but for others outside of this narrow field, employing the word 'transition' may disconnect the process from some of its complexity.

I suggest, therefore, that the word 'limbo' is a valuable aid in conveying the ambiguities of the transition from military to civilian life. To suggest such a shift is, however, a daunting task since psychology and sociology are the dominant research paradigms on this topic. But through the lens of pastoral psychology, care, and counseling, this is an especially fertile path to embark upon because limbo is a theologically connoted concept that can encapsulate experiences of benefits (of not being committed to mandatory postings, deployments, hierarchy, and ranks) as well as liabilities (of being disoriented, lost, confused, adrift, useless, without purpose, and/or unable to make decisions or achieve desired goals). Former service members may find themselves feeling confined or neglected or even as though they are living in a state of oblivion after leaving their military communities and battle buddies. Civilian societies may have little or no interest, at least through the eyes of veterans, in fully acknowledging and recognizing former service members for the sacrifices they have made in the line of duty (Brock and Lettini 2012; Lifton 1992; Shay 2002, 2003). Thus, the word 'limbo' may capture a profound experience among veterans of being in between, not fully a military service member and not fully a civilian citizen; limbo is not heaven, neither is it hell, but rather it is a darker, in-between place, somewhere between military and civilian borders.

By utilizing the limbo lens in pastoral psychology, we can draw from a theological tradition of wisdom, with a specific interest in pastoral care and counseling, that can be traced across centuries back to the Middle Ages. Even though this concept was never officially adopted by the Roman Catholic Church, it is nonetheless a concept that is deeply rooted and is widespread far beyond the Roman Catholic domain. Additionally, since it is not an official church teaching, the idea of limbo is also free of ecclesiastical constraints and thereby available for anyone's reflective application to human life.

Through the above review and presentation of qualitative research data from North American, British, and Scandinavian contexts, it is suggested that leaving military service implicates rather similar challenges for service members worldwide. These issues take time to process and may prove to be taxing for veterans. Even if new meaningful identities, jobs, and lives are eventually found and shaped within a civilian context and society, military positions may well continue to exist and act within the self, as illustrated in the Reconsidering the Uniform study (Grimell 2018a). Further development of the concept of living in limbo could be a compelling aid in deepening the understanding of the process and may resonate better with the experiences of some former service members. This expression could also resonate with veterans in highly secularized contexts such as Sweden since many nonreligious adults still harbor a good understanding of limbo; Dante's (2009) Divine Comedy is commonly read in schools, and the concept/expression of limbo is further popularized in films.

Ascribing and employing the concept of living in limbo to qualitative experiences of transition from military to civilian life can help to put words to varying degrees of distress (e.g., anxiety, worry, impatience, frustration, conflict, anger, dread, and despair) felt in this process. Building upon the foundation laid by Capps and Carlin (2010), it is suggested that the transition to civilian life may involve most of the examples of acute limbo situations presented in their approach (pp. 3-5). This demonstrates that living in limbo after military service is a potentially very complex situation with parallel and simultaneous processes to consider. For 
example, within committed relationships both a former service member and his or her partner/ spouse (and other family members) may struggle with losses and hopes and attempts at reorientation, renegotiation, and reconnection. A veteran may grapple with grief over the loss of battle buddies, sacrifices imposed upon the family, and difficulties transcending military life in order to further nurture and build the identities and emotions of a present partner/husband/ father (Grimell 2019; Sippola et al. 2009; Stallinga 2013). The partner or spouse may struggle with feelings of being neglected for a long time simultaneously with hopes of a new future together (Beder 2012; Moore 2012; Segal 1986). Both may be well served by pastoral counseling and intrapersonal and interpersonal reconciliation and atonement, which can help them to reconnect and thrive together.

Furthermore, the job hunt, including interviews and the realization of having lost not only a vocation but also the meaning ascribed to their military service, can be daunting, difficult, and burdensome. Another acute limbo situation that may be encountered within this overall process involves physical and emotional illnesses such as the development of PTSD and/or moral injury (see Doehring and Ramsay 2019; Graham 2017; Moon 2019; Rambo 2010). These may also be a motive for discharge yet may manifest later in civilian life. Finally, the transition to civilian life may involve potent feelings of dislocation and disorientation. This may be coupled with PTSD but in the case of limbo may revolve around military cultural mind-sets and experiences that produce feelings of not being at home in the civilian context, wherein that which was formerly seen as right now makes no or very little sense and the military ideas of identity, meaning, and purpose are both questioned and considered irrelevant.

Finally, in line with Capps (1998), much of the pastoral counseling within congregations and religious communities is not particularly comprehensive. Advanced and specialized counseling and counselors tend to be found instead within pastoral counseling centers. Yet pastoral counseling is essential to the life of congregations (Capps 1998). Even so, veterans and/or their partners who seek pastoral counseling in the context of their religious communities for matters regarding readjustment to civilian life may not feel inspired to engage in 15 to 20 sessions. The pastor who works in a congregation may also have limited time to offer a care receiver and may also have limited counseling experience in general and scant knowledge of veterans in particular. One to three sessions may be more plausible for the pastor and the care seekers alike. This may prove sufficient, and some even suggest that "pastoral counseling should, for various reasons, consist of very few sessions or meetings" (Capps 2001, p. 4). This suggests that there is a need for a general pastoral psychological construct that can be employed both in the interest of supporting and guiding care seekers in acute limbo situations and to assist pastors as much as possible in their counseling. Living in limbo can be such a pastoral psychological construct, one that may resonate with veterans and/or their significant others. This construct can also assist with continued reflection and discussion, beyond the context of counseling and the concept of transition, in order to find paths through acute limbo situations that can, in the long run, enhance the religious/spiritual lives of veterans.

\section{Concluding remarks}

Qualitative evidence demonstrates an ambiguity in the transition from military to civilian life that can be described as living in limbo. The concept of living in limbo introduces an open and general pastoral psychological understanding of the transition to civilian life that can resonate with both the experiences of former service members as well as of their partners, spouses, and other family members. Living in limbo can apply to everyone left behind when an individual 
enters service, so leaving military service is potentially a joint process that impacts, influences, and includes entire families. The pastoral psychological construct of limbo has the potential to nurture mutual understandings that may support an initial step to firmer ground. From a theological perspective, even if the road is long and grace feels distant, this is not a situation devoid of grace. Living in limbo may be a highly complex situation for veterans and can include simultaneous processes that may be coupled with the need for forgiveness, reconciliation, and atonement with the self as well as with significant others.

Open Access This article is distributed under the terms of the Creative Commons Attribution 4.0 International License (http://creativecommons.org/licenses/by/4.0/), which permits unrestricted use, distribution, and reproduction in any medium, provided you give appropriate credit to the original author(s) and the source, provide a link to the Creative Commons license, and indicate if changes were made.

\section{References}

Adler, A. B., Britt, T. W., Castro, C. A., McGurk, D., \& Bliese, P. D. (2011a). Effect of transition home from combat on risk-taking and health-related behaviors. Journal of Traumatic Stress, 24(4), 381-389.

Adler, A. B., Zamorski, M., \& Britt, T. W. (2011b). The psychology of transition: Adapting to home after deployment. In A. B. Adler, P. B. Bliese, \& C. A. Castro (Eds.), Deployment psychology: Evidence-based strategies to promote mental health in the military (pp. 153-174). Washington, DC: American Psychological Association.

American Psychiatric Association. (2013). Diagnostic and statistical manual of mental disorders (5th ed.). Washington: Author.

Beder, J. (Ed.). (2012). Advances in social work practice with the military. New York: Routledge, Taylor \& Francis Group.

Ben-Ari, E. (1998). Mastering soldiers: Conflict, emotions, and the enemy in an Israeli military unit. New York: Berghahn Books.

Blackburn, D. (2017). Out of uniform: Psychosocial issues experienced and coping mechanisms used by veterans during the military-civilian transition. Journal of Military, Veteran and Family Health, 3(1), 1-8. http://jmvfh.utpjournals.press/doi/pdf/10.3138/jmvfh.4160. Accessed 15 Aug 2017.

Bobrow, J., Cook, E., Knowles, C., \& Vieten, C. (2013). Coming all the way home: Integrative community care for those who serve. Psychological Services, 10(2), 137-144.

Bragin, M. (2010). Can anyone here know who I am? Co-constructing meaningful narratives with combat veterans. Clinical Social Work Journal, 38(3), 316-326.

Brock, R. N., \& Lettini, G. (2012). Soul repair: Recovering from moral injury after war. Boston: Beacon Press.

Brunger, H., Serrato, J., \& Ogden, J. (2013). "No man's land": The transition to civilian life. Journal of Aggression, Conflict and Peace Research, 5(2), 86-100.

Bryan, C. J., \& Morrow, C. E. (2011). Circumventing mental health stigma by embracing the warrior culture: Lessons learned from the Defender's edge program. Professional Psychology: Research and Practice, 42(1), 16-23.

Burkhart, L., \& Hogan, N. (2015). Being a female veteran: A grounded theory of coping with transitions. Social Work in Mental Health, 13(2), 108-127.

Capps, D. (1995). Agents of hope: A pastoral psychology. Minneapolis: Augsburg Fortress.

Capps, D. (1998). Living stories: Pastoral counseling in congregational context. Minneapolis: Augsburg Fortress Press.

Capps, D. (2001). Giving counsel: A minister's guidebook. St. Louis: Chalice Press.

Capps, D., \& Carlin, N. (2010). Living in limbo: Life in the midst of uncertainty. Eugene: Cascade Books.

Coll, J. E., Weiss, E. L., \& Yarvis, J. S. (2012). No one leaves unchanged-Insights for civilian mental health care: Professionals into the military experience and culture. In J. Beder (Ed.), Advances in social work practice with the military (pp. 18-33). New York: Routledge, Taylor \& Francis Group.

Dante, A. (2009). The divine comedy (Trans. by H. F. Cary). Ware, Hertfordshire, England: Wordsworth Editions.

De La Torre, M. A. (2017). Embracing hopelessness. Minneapolis: Fortress Press.

Devries, M. R., Hughes, K. H., Watson, H., \& Moore, B. A. (2012). Understanding the military culture. In B. A. Moore (Ed.), Handbook of counseling military couples (pp. 7-18). New York: Routledge, Taylor and Francis Group.

Doehring, C., \& Ramsay, N. J. (2019). Introduction to the special issue on military moral injury. Pastoral Psychology, 68(1), 1-2.

Drescher, K. D., Foy, D. W., Kelly, C., Leshner, A., Schutz, K., \& Litz, B. (2011). An exploration of the viability and usefulness of the construct of moral injury in war veterans. Traumatology, 17(1), 8-13. 
Drops, G. J. (1979). Change in self-concept and identity during a time of mid-life transition. (Doctoral dissertation, Union for Experimenting Colleges and Universities, Union Graduate School West, San Diego).

Graham, L. K. (2017). Moral injury: Restoring wounded souls. Nashville: Abingdon Press.

Grimell, J. (2018a). Reconsidering the uniform: Existential and religious identity reconstruction among Swedes in the aftermath of military service (Doctoral dissertation, Vrije Universiteit Amsterdam, the Netherlands). Zürich, Switzerland: LIT Verlag.

Grimell, J. (2018b). Veterans, the hidden wounds of war, and soul repair. Spiritual Care, 7(4), 353-363.

Grimell, J. (2019). Suffering for others while making others suffer: Military narratives of sacrifice. Pastoral Care \& Counseling, 73(1), 30-40.

Hall, L. K. (2012a). The importance of understanding military culture. In J. Beder (Ed.), Advances in social work practice with the military (pp. 3-17). New York: Routledge, Taylor \& Francis Group.

Hall, L. K. (2012b). The military lifestyle and the relationship. In B. A. Moore (Ed.), Handbook of counseling military couples (pp. 137-156). New York: Routledge, Taylor and Francis Group.

International Theological Commission of the Roman Catholic Church. (2007). The hope of salvation for infants who die without being baptized. http://www.vatican.va/roman_curia/congregations/cfaith/cti_documents/rc_ con cfaith doc 20070419 un-baptised-infants en.html. Accessed 8 Dec 2018.

Koenig, H. G., Boucher, N. A., Oliver, J. P., Youssef, N., Mooney, S. R., Currier, J. M., \& Pearce, M. (2017). Rationale for spiritually oriented cognitive processing therapy for moral injury in active duty military and veterans with posttraumatic stress disorder. Journal of Nervous and Mental Disease, 205(2), 147-153.

Liebert, E. A. (2019). Accessible spiritual practices to aid in recovery from moral injury. Pastoral Psychology, $68(1), 41-57$.

Lifton, R. J. (1992). Home from the war: Learning from Vietnam veterans (with a new preface and epilogue on the Gulf war). Boston: Beacon Press.

Lindsay, C. B., Hodgson, T. J., Krikheli, L., Soh, R. Y., Armour, A.-R., Singh, T. K., \& Impiombato, C. G. (2016). Moral injury, spiritual care and the role of chaplains: An exploratory scoping review of literature and resources. Journal of Religion and Health, 55, 1218-1245.

Litz, B. T., Stein, N., Delaney, E., Lebowitz, L., Nash, W. P., Silva, C., \& Maguen, S. (2009). Moral injury and moral repair in war veterans: A preliminary model and intervention strategy. Clinical Psychology Review, 29(8), 695-706.

Moon, Z. (2015). Coming home: Ministry that matters with veterans and military families. St. Louis: Chalice Press.

Moon, Z. (2019). Warriors between worlds: Moral injury and identities in crisis. Lanham: Lexington Books.

Moore, B.A. (Ed.). (2012). Handbook of counseling military couples. New York: Routledge, Taylor and Francis Group.

Rambo, S. (2010). Spirit and trauma; A theology of remaining. Louisville: Westminister John Knox Press.

Savion, S. M. (2009). How do retired officers start anew in civilian society? A phenomenological study of life transition (Doctoral dissertation, George Washington University, Washington, DC). https://scholarspace. library.gwu.edu/concern/gw_etds/cj82k7352. Accessed 14 Dec 2018.

Segal, M. (1986). The military and the family as greedy institutions. Armed Forces and Society, 13(1), 9-38.

Shay, J. (2002). Odysseus in America: Combat trauma and the trials of homecoming. New York: Scribner.

Shay, J. (2003). Achilles in Vietnam: Combat trauma and the undoing of character. New York: Scribner.

Sippola, J. W., Blumenshine, A., Tubesing, D. A., \& Yancey, V. (2009). Welcome them home-help them heal: Pastoral care and ministry with service members returning from war. Duluth: Whole Person Associates.

Stallinga, B. A. (2013). What spills blood wounds spirit: Chaplains, spiritual care, and operational stress injury. Reflective Practice: Formation and Supervision in Ministry (Vol. 33, pp. 13-31).

Strachan, H. (2006). Morale and modern war. Journal of Contemporary History, 41(2), 211-227.

Tick, E. (2005). War and the soul: Healing our nation's veterans from post-traumatic stress disorder. Wheaton: Theosophical Publishing House.

Verey, A., \& Smith, P. K. (2012). Post-combat adjustment: Understanding transition. Journal of Aggression, Conflict and Peace Research, 4(4), 226-236.

Verrips, J. (2006). Dehumanization as a double-edged sword. In G. Baumann \& A. Gingrich (Eds.), Grammars of identity/alterity: A structural approach (pp. 142-154). New York: Berghahn Books.

Wilson, P. H. (2008). Defining military culture. Journal of Military History, 72(1), 11-41.

Woodward, R. (2008). Not for queen and country or any of that shit. In D. Cowen \& E. Gilbert (Eds.), War, citizenship, territory (pp. 363-384). New York: Routledge.

Wortmann, J. H., Eisen, E., Hundert, C., Jordan, A. H., Smith, M. W., Nash, W. P., \& Litz, B. T. (2017). Spiritual features of war-related moral injury: A primer for clinicians. Spirituality in Clinical Practice, 4(4), $249-261$.

Yanos, R. C. (2004). Perceptions of transition to civilian life among recently retired Air Force officers (Doctoral dissertation, University of Maryland, College Park MD). http://drum.lib.umd.edu/handle/1903/2321. Accessed 8 Aug 2017.

Publisher's Note Springer Nature remains neutral with regard to jurisdictional claims in published maps and institutional affiliations. 